\section{Inhibition of the rod-and-frame effect by circular contours}

\author{
SHELDON M. EBENHOLTZ \\ and JOHN W. UTRIE, JR. \\ University of Wisconsin, Madison, Wisconsin
}

When a large surrounding frame is tilted in the frontal plane, an upright observer feels tilted oppositely to the orientation of the frame (Ebenholtz \& Benzschawel, 1977; Sigman, Goodenough, \& Flanagan, 1979), and a line-target seen within the frame requires adjustment in the direction of the frame in order to appear upright (Witkin \& Asch, 1948).

These effects appear to be isolated from the perceptual processing stages associated with form organization (Streibel, Barnes, Julness, \& Ebenholtz, 1980), apparent size (Ebenholtz, 1977), and the depth relation between line and frame (Ebenholtz \& Glaser, 1982). The frame may thus be regarded as the visual input to an automatic orientation control system having visual, vestibular, and proprioceptive channels (e.g., Parker, 1980).

It has long been known that individuals vary widely in the degree of influence of the frame on orientation perception, and it has been thought that this variability reflects a central characteristic known as perceptual or cognitive style (Witkin \& Goodenough, 1981; Witkin, Oltman, Raskin, \& Karp, 1971). Although recent evidence casts doubt on the presence of a relation between perceptual style as measured by the Embedded Figures Test (Witkin et al., 1971) and the rod-and-frame task (Streibel \& Ebenholtz, 1982), there is no doubt that performance on the latter represents a highly reliable individual characteristic that persists over long time intervals (Witkin, Goodenough, \& Karp, 1967). Despite its stability, however, we have found that the RFE can be altered radically within individuals. We provide evidence below that surrounding the frame with a circular luminous contour serves to modulate the influence of the tilted frame.

Twenty-four volunteer subjects, 16 females and 8 males who were naive to the task, took part. The task was to adjust a luminous rod to the egocentric vertical defined as the chin-forehead and 6 to 12 o'clock direction. The rod, $195.5 \mathrm{~cm}$ in length, rotated about an axis at the center of a frame $106.5 \mathrm{~cm}$ per side. The frame was tilted $22 \mathrm{deg}$ clockwise and was viewed from a distance of $153.5 \mathrm{~cm}$. The luminous circle had an outer diameter of $162 \mathrm{~cm}$ and a width of $1.4 \mathrm{~cm}$, and was viewed from a distance $2.5 \mathrm{~cm}$ farther than the frame. For half the subjects, the rod was first adjusted

The authors' mailing address is: Department of Psychology, University of Wisconsin, Madison, Wisconsin 53706. alone, followed by adjustments made in the presence of the tilted frame. Differences in the frame-present and frame-absent settings defined the rod-and-frame effect (RFE). These were followed by rod settings in the absence of the frame but with the circle present, and finally with both frame and circle present. The remaining subjects performed in the reverse sequence, that is, the two circle conditions first.

The Grant test (Grant, 1949) revealed no significant sequence effects $[F(1,22)=1.16, p>.05]$, but the presence or absence of the circumscribing circle produced a highly significant difference $[F(1,22)=49.36$, $p<.01]$. The data, pooled over sequence, are represented in Figure 1, in which the total sample and the highest and lowest thirds according to performance on the frame-alone condition are shown. Both high and low scorers were significantly influenced by the circumscrib.

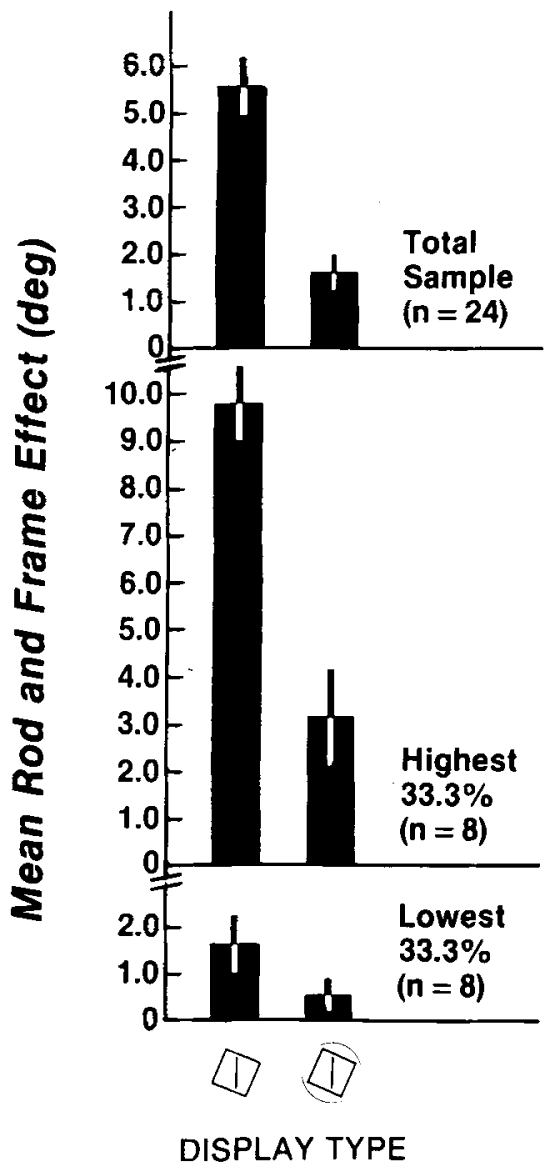

Figure 1. Mean rod-and-frame effect by display type. Top panel represents data of all subjects. Middle and bottom panels represent, respectively, the highest and lowest scoring terciles according to performance on the frame-alone condition. Positive acorea indicate tilt in the direction of the frame. Vertical bar indicates $\pm 1 \sigma_{\mathrm{M}}$ : 
ing pattern $[\mathrm{t}(7)=11.06$ and 1.87 , respectively, with $\mathrm{p} \leqslant .05$ in each case]. Overall, only two subjects, both low scoring, failed to show a reduced RFE under the circle condition, the net result of which was to reduce the RFE to $27.9 \%$ of initial level.

It is clear that the presence of the circular pattern around the frame inhibits the influence of the tilted frame on egocentric orientation. The more general role of such a phenomenon in the orientation control system, especially in the control of posture and vection, remains to be explored.

\section{REFERENCES}

Ebenholtz, S. M. Determinants of the rod and frame effect: The role of retinal size. Perception \& Psychophysics, 1977, 22, 531-538.

Ebenholtz, S. M., \& Benzschawel, T. L. The rod and frame effect and induced head tilt as a function of observation distance. Perception \& Psychophysics, 1977, 13, 491-496.

Ebenholtz, S. M., \& Glaser, G. W. Absence of depth processing in the large-frame rod-and-frame effect. Perception \& Psychophysics, 1982, 32, 134-140.

Grant, D. A. The statistical analysis of a frequent experimental design. American Journal of Psychology, 1949, 62, 119-122.
Parker, D. The vestibular apparatus. Scientific American, 1980, 243, 118-134.

Sigman, E., Goodenough, D. R., \& Flannagan, M. Instructions, illusory self-tilt, and the rod-and-frame test. Quarterly Journal of Experimental Psychology, 1979, 31, 155-165.

Streibel, M. J., Barnes, R. D., Julness, G. D., \& Ebenholtz, S. M. Determinants of the rod-and-frame effect: Role of organization and subjective contour. Perception \& Psychophysics, 1980, 27, 136-140.

Streibel, M. J., \& Ebenholtz, S. M. Construct validity of perceptual style: Role of stimulus size in the embedded-figures test and the rod-and-frame test. Perception \& Psychophysics, 1982, 31, 128-138.

Witkın, H. A., \& Asch, S. E. Studies in space orientation: IX. Further experiments on perception of the upright with displaced visual fields. Journal of Experimental Psychology, 1948, 38, 762-782.

Witkin, H. A., \& Goodenovgh, D. R. Cognitive styles: Essence and origins. New York: International Universities Press, 1981.

Witkin, H. A., Goodenough, D. R., \& KarP, S. A. Stability of cognitive style from childhood to young adulthood. Journal of Personality and Social Psychology, 1967, 7, 291-300.

Witkin, H. A., Oltman, P. K., Raskin, E., \& KarP, S. A. A manual for the Embedded Figures Test. Palo Alto, Calif: Consulting Psychologists Press, 1971.

(Manuscript received June 1, 1982; accepted for publication June 7,1982 .) 